\title{
El temor a la racionalidad instrumental
}

\section{Fear of instrumental rationality}

DOI: $10.46932 / \mathrm{sfjdv2n2-057}$

Received in: january 1st, 2020

Accepted in: March 30th, 2020

\author{
Salvador Mancillas Rentería \\ Grado: Doctorado \\ Lugar de Trabajo: Universidad Autónoma de Nayarit \\ Domicilio: Ciudad de la Cultura "Amado Nervo" \\ E-mail: salvadormancillas@uan.edu.mx
}

\begin{abstract}
RESUMEN
El presente trabajo expone la capa mitológica moderna que esconde el miedo a la maquinización de la vida social. Las relaciones despersonalizadas y la cosificación de todo tipo de procesos, productivos y organizacionales, constituyen una realidad, cuyas precarias salidas son las válvulas de escape de las narrativas estéticas y cinematográficas. No obstante, se sugiere que -encerrados en esa jaula de hierro utilitaria que es la sociedad- se esconde una verdad que suele pasar desapercibida: la tecnología y las máquinas de las que tanto renegamos, poseen una función liberadora, intuida ya hace más de dos mil años por Aristóteles. Se vislumbra, entonces, que una tarea emancipadora de la sociedad no dependería de luchar contra la maquinización y la «razón instrumental», como proponía el programa de la Escuela de Frankfurt, sino todo lo contrario. Se requiere un proyecto político y social que busque sistemática y deliberadamente la automatización absoluta de la sociedad, precisamente para liberar al hombre de ser un apéndice de sus propios procesos.
\end{abstract}

Palabras clave: Tecnología, razón instrumental, maquinización, despersonalización, liberación.

\begin{abstract}
This paper exposes the modern mythological layer that hides the fear of the mechanization of social life. Depersonalized relationships and the reification of all kinds of processes, productive and organizational, constitute a reality, whose precarious exits are the escape valves of aesthetic and cinematographic narratives. Nevertheless, it is suggested that -enclosed in that utilitarian iron cage that is society- a truth that usually goes unnoticed is hidden: technology and the machines that we so much disown have a liberating function, intuited more than two thousand years ago by Aristotle. It can be seen, then, that an emancipating task of society would not depend on fighting against mechanization and "instrumental reason", as proposed by the Frankfurt School program, but quite the opposite. It requires a political and social project that systematically and deliberately seeks the absolute automation of society, precisely in order to free man from being an appendage of his own processes.
\end{abstract}

Key words: Technology, instrumental reason, mechanization, depersonalization, liberation.

\section{EL EFECTO CATÁRTICO DE LA CULTURA DE MASAS}

La película «Tiempos modernos» (1936) de Charles Chaplin, donde Charlot aparece adherido bocabajo a un enorme engranaje, sometido al movimiento monótono de la cadena de montaje de una 
fábrica, constituye una imagen poderosa de la cultura contemporánea que pinta el lado aterrador del capitalismo. La reducción del hombre a simple pieza mecánica dentro del conjunto cosificado de la producción, es resultado de procesos sociales que escapan al entendimiento de la mayoría de los seres humanos y alimentan, por ende, los miedos metafísicos característicos del mundo moderno.

A dos décadas del siglo veintiuno, para nadie son desconocidas las inquietudes de filósofos y sociólogos acerca del destino de una sociedad humana dominada por la «razón instrumental», la tecnología y los procesos burocráticos o productivos cada vez más impersonales que «desnaturalizan»al ser humano y, en muchos casos, le producen patologías psicológicas y biológicas que arruinan su calidad de vida. El estrés laboral, la depresión, el suicidio y la descomposición familiar son algunos de los efectos catastróficos y descorazonadores del mundo moderno que preocupan desde hace más de un siglo a pensadores, científicos y estadistas.

Dentro de la sociología clásica, Max Weber se refería en su Ética protestante (2004) al mundo moderno como una «jaula de hierro» ${ }^{*}$ en la que los individuos estamos atrapados sin esperanza. El cálculo, la cosificación de los seres humanos y la organización social construida en una lógica funcional o, más bien, maquinal, someten al hombre a una existencia desencantada, atomizada y burocratizada. Para Weber, la burocracia es una forma de dominación en tanto que establece condiciones de obediencia en una estructura vertical constituida por funciones jerárquicas, sea en el estado o en el ámbito fabril, cuyas reglas tienden a la totalización del dominio social. Los valores promovidos se refieren a la eficiencia en el cumplimiento de las tareas, así como al cálculo de beneficios económicos y políticos, lo que garantiza que esta «jaula de vínculos de hierro» atrape a los seres humanos en cuerpo y alma, por dentro y por fuera; es decir, domine tanto la dimensión subjetiva como la objetiva de los individuos.

Un poco después de Weber, los filósofos de la escuela de Frankfurt, Adorno y Horkheimer, creyeron identificar una relación rígida entre progreso y deshumanización, que trae como resultado enajenación y falta de libertad, pérdida de autodeterminación e incapacidad de resistir los poderes externos, encarnados en la maquinaria del estado y en las formas «burguesas» de control social. Para la escuela de Frankfurt, un retorno a la humanización de la vida social sería posible mediante un programa crítico de emancipación que parta de la razón subjetiva, y no de la razón instrumental u objetiva. Esta última tiende a someter a la naturaleza y a la sociedad de un modo paradójico: por un lado, atiza la incertidumbre y los sentimientos de zozobra del mundo modernizado; pero por el otro nos obliga a entregamos sin resistencia, chantajeados por la urgencia de sobrevivir.

\footnotetext{
* Weber no mencionó expresamente esa metáfora; se refirió más bien a un “duro caparazón de acero" que Talcott Parsons tradujo al inglés como "iron cage". Al respecto, escribe el profesor Eduardo Fidanza en su artículo La jaula de hierro cien años después (2004), siguiendo a Hans Blumenberg: «En rigor, estaríamos en presencia de una superposición de confusiones, o de interpretaciones discutibles, que, paradójicamente, fueron convenientes para asegurar fama duradera tanto a la "jaula de hierro" como a La ética».
} 
Una vez introducidos en la jaula de la realidad, el torbellino cotidiano nos adormece con la costumbre, mientras los miedos originales se trasladan al imaginario colectivo y representacional del arte, en especial la literatura y el cine, para mediatizar las conciencias. Los mecanismos de normalización son variados. En la esfera del arte, por ejemplo, se recrean los terrores míticos de la modernidad en procesos catárticos, estéticos, para ser liberados momentáneamente en la fantasía mediante el recurso de actantes heroicos. Los comics, el cine y la literatura nos persuaden de que la bondad, el amor y otros sentimientos idealizados, plasmados en héroes y personajes protagónicos, son irreductibles a la realidad maquinal y tecno-diabólica creada por malvados científicos y otros demonios modernos, y constituyen, por tanto, un ápice de esperanza al que se puede apelar, inclusive al borde del infierno.

En efecto, las personas comunes y corrientes, al contrario de Weber y los filósofos de la escuela de Frankfurt, percibimos desde generaciones atrás ese mismo lado «perverso» del capitalismo, no a partir de sesudas reflexiones, sino a través de la cultura de masas, en especial la literatura y el cine. Nos son familiares algunos íconos universales, como el Frankenstein de Mary Shelley, los relatos acerca de científicos controladores del mundo —tan comunes en los comics—, así como de pandemias que amenazan con extinguir la vida humana. La invasiva cultura de masas, además de constituirse en una industria lucrativa, tiene esa función estéticamente purificadora, en la que los poderes reales y destructores del sistema capitalista se banalizan en imágenes ficticias y tranquilizan momentáneamente, por consiguiente, a sus consumidores. La cultura de masas ha usurpado a la religión una de sus funciones: conjurar el sentimiento de incertidumbre, pero ya sin el ropaje de la trascendencia divina. A cambio de esta carencia trascendental, el espectador se queda con la viva impresión de que el mal puede ser combatido e incluso eliminado por métodos terrenales, a condición de ser motivados por el plus de la bondad, la justicia y el amor.

Aun cuando sean posibles las guerras apocalípticas, pletóricas de armas inusitadas, o de máquinas destructivas manejadas por entes robotizados que, de alguna manera misteriosa, son capaces de actuar con el poder destructor de la maldad humana, nos queda la impresión de que esos poderes son materiales y pueden, por tanto, ser enfrentados mediante poderes espirituales antagónicos.

Toda cultura crea sus mitos y la modernidad no es la excepción. Esos mitos se refieren a una realidad de fondo, donde el poder material y científico está vinculado a consecuencias indeseables y catastróficas para el conjunto de la sociedad humana. Lo curioso es que, al final de cuentas, se trata del mismo núcleo referencial de la sociología clásica y crítica, para la cual el progreso tecno-científico trae como nefasta consecuencia la deshumanización de la vida.

\section{LA CONJETURA ARISTOTÉLICA SOBRE EL PAPEL LIBERADOR DE LAS MÁQUINAS}


Las películas de Chaplin y del expresionismo alemán, así como la literatura distópica —las novelas del genial Yevgueni Zamiantin, Aldous Huxley y George Orwell— han pintado, pues, una realidad incierta y angustiante que con el paso del tiempo ha terminado por modelar las mentalidades (y emociones) estándar de nuestros contemporáneos, en cuyo imaginario figuran tecnólogos y burócratas despóticos, científicos locos, así como criaturas de laboratorio que escapan al control humano, con las consecuencias fatales del caso. Después de todo, esas narrativas estéticas nos ayudan a comprender, aunque sea de forma maniquea, el lado siniestro de la modernidad. En ninguna de esas narrativas falta, en efecto, la figura heroica destinada a proporcionar el mecanismo catártico que nos haga, un poco, recuperar cierta sensación de seguridad. En todo caso, siempre se relata algún intento de rebelión contra un estado de cosas que se considera básicamente inhumano. Es decir, siempre hay un acto de amor que busca algo parecido a la redención, que representa la salvación de toda la especie a partir de las cualidades individuales de personajes protagónicos. Para disipar la zozobra, se deja la posibilidad de conservación de la vida en condiciones armónicas.

Convertido el mundo en una máquina universal constituida por procesos impersonales, la solidaridad, la empatía y el amor son sentimientos cada vez más raros, lo que convierte propiamente la vida en un infierno. La despersonalización es, sin duda, el rasgo más repugnante de la modernidad y el capitalismo. No sólo esclaviza al someternos en sus procesos maquinales, sino que vacía el alma humana al robotizar y predeterminar nuestras acciones productivas y de gestión social. Weber reaccionó con perplejidad a esta característica del mundo moderno y Anthony Giddens trató de explicarlo, como veremos, con el concepto de desanclaje. En las narrativas estéticas se trata, mientras tanto, de recuperar el «mundo original» o el estado de cosas «natural», tal como nos lo confió Dios, para conjurar los males de la despersonalización. En la novela «1984», de George Orwell, los personajes centrales Julia y Winston Smith, son los amantes que desafían al sistema totalitario que prohíbe amar a cualquiera que no sea al gran hermano (Big Brother), el máximo centro de poder de la sociedad. En una vida sin dioses, toda forma de culto en Oceanía —el país totalitario imaginado por Orwell- es sometido por una entelequia impersonal, invisible y central del sistema de poder, que ni siquiera tiene un nombre de pila; simplemente es el gran hermano, un símbolo de desangelada, fría y falsa fraternidad.

Julia y Winston, que se entregan a una forma de amor prohibido, es decir, el natural y espontáneo, son perseguidos y torturados dramáticamente, precisamente porque el sistema es tan totalitario que busca controlar, con procedimientos sofisticados, no sólo lo que cada habitante piensa, sino también lo que siente. Los sentimientos y las emociones son fiscalizados porque constituyen un factor subversivo. En un mundo así, no hay redención posible y es fácil prever que los protagonistas terminen asimilados al estado totalitario mediante el lavado de cerebro y otros medios de control. 
Mientras tanto, el héroe indiscutible de la novela «un mundo feliz» de Huxley es, sin duda, John el salvaje, aunque sólo sea también en situaciones sucesivamente trágicas. A nivel simbólico, el salvaje representa lo indomeñable de la naturaleza, sus singularidades imposibles de estandarizar y, por tanto, las expresiones del misterio último e insondable de la vida, irreductibles a la voluntad científica y a cualquier sistema social, -por perfecto, tecnificado y planificado que resulte-; de hecho, John es considerado un error de la naturaleza; casi una mutación desagradable producto del imperfecto uso de los métodos anticonceptivos prescritos por el estado. En suma, es un resultado imprevisto, un proceso natural que se sale del control técnico, de ahí su carácter aberrante. Es importante subrayar esto, puesto que, para la razón instrumental, cualquier cosa que se sale de control es fuente de incertidumbre: es algo que hay que eliminar o por lo menos neutralizar para evitar consecuencias nefastas para el sistema. No son, pues, las máquinas automáticas en sí mismas las que generan mitos terroríficos, sino la posibilidad de que las cosas y el comportamiento de los seres escapen a lo previsto, a lo predeterminado por los programas diseñados desde los centros corporativos de poder: es el miedo a que lo singular e irregular provoquen el colapso del sistema que sustenta y promueve los procesos maquinales. El sistema capitalista no teme a las consecuencias ecológicas, a la injusticia distributiva, a la depauperización de la vida; teme que se detengan los procesos que hacen funcionar el intercambio de bienes, el mundo de las finanzas, del mercado, y los procesos institucionales burocratizados. Mantener este orden es mantener el poder. La vida social en su conjunto debe mantenerse funcionalmente determinada por la lógica utilitaria y de cálculo, en todos los estratos.

Lo criticable del capitalismo no es que se sustente en una producción masiva apoyada en la ciencia y la tecnología; al final de cuentas, escribe Theodor Adorno en su crítica a Brave new world (título en inglés de «El mundo feliz»), los bienes de la modernidad tienen la posibilidad de garantizar una «vida segura y cómoda». Lo deplorable es que, como organización social y económica, el capitalismo moderno produzca capas enteras de seres humanos que permanecen en espantosa miseria; y encima de todo ello, las adapte a las condiciones de injusticia, aceptando la paz dudosa impuesta por sus «astutas élites» (T. Adorno 1962: 115).

«El gabinete del doctor Caligari», película de los años veinte del siglo pasado, más allá de las cualidades estéticas y cinematográficas subrayadas por los críticos, nos parece también una obra importante en cuanto se erige en la suprema metáfora del condicionamiento social de la conducta, en la que el hombre se convierte en instrumento de ejecución de fines ajenos. Lo mismo da ser el apéndice de una máquina, al estilo de Charlot, que el medio por el cual un hipnotista manipulador obliga al sonámbulo Cesare —infortunado personaje del film— a asesinar a las personas que el enigmático Caligari le indica. Ambos casos apuntan también a la instrumentalización de las relaciones sociales, esto es, a la organización 
maquínica de la sociedad. Si se nos permite seguir la analogía, el burgués es una especie de Caligari que controla, mediante tecnología organizacional y material, a los obreros, con la finalidad de producir plusvalor y aumentar, así, su riqueza a costa del deterioro físico de sus operadores. Lo mismo vale para el estado, que produce funcionarios y reglas para ser cumplidas por los miembros de una nación, con base en el principio del monopolio de la violencia y la jerarquización de las funciones, siempre vigiladas por un panóptico o un Big Brother que ve a todos sin ser visto él mismo nunca.

Por cierto, «el gabinete del doctor Caligari», dirigida por Robert Wiene, adelanta esa idea del condicionamiento social, que Aldous Huxley introducirá en su novela «mundo feliz», como parte esencial de los mecanismos de dominio del estado totalitario. Se trata precisamente de la «hipnopedia» aplicada a los niños, técnica sofisticada para introducir en la mente y la imaginación ideas y figuras apropiadas, es decir, acordes a los intereses del sistema. El narrador de la novela comenta que «el condicionamiento sin palabras (como el aplicado a los ratones de Skinner) es algo tosco y burdo; no puede hacer distinciones más sutiles, no puede inculcar las formas de comportamiento más complejas», explica. «Para esto se precisan las palabras, pero palabras sin razonamiento. En suma, la hipnopedia» (Huxley A. 2020: 22, 23). La producción en serie, el condicionamiento del aprendizaje, la estandarización de la conducta, la reproducción biológica maquinal y el control central, jerarquizado, de la sociedad mundial son los elementos distópicos que resaltan en el mundo pintado por Huxley. Ahí, la ciencia y la tecnología existen sólo para producir una felicidad artificial, uniformada y, por ende, vacía, como la que produce la cultura de masas.

¿Realmente ese terror pánico de la sociedad contemporánea está justificado? ¿Debemos temer a esa racionalidad instrumental que parece atraparnos en un mundo tejido de relaciones incomprensibles, prácticamente desde el nacimiento o quizá antes? ¿o puede existir algún indicio capaz de persuadirnos de que ese miedo es infundado?

Si revisamos la historia, nos daremos cuenta de que esta predisposición contra lo mecánico no es exclusiva del mundo moderno. En el mundo clásico, Aristóteles reconocía en su Física una causalidad eficiente en la naturaleza, es decir, la existencia de procesos naturales o artificiales capaces de operar con precisión, pero articuladas en el conjunto de las restantes causas, donde la principal y, por ende, más importante, era la causa final.

En ese marco de razonamiento multicausal (tan ajeno al moderno), una máquina artificial, en tanto que carece por sí misma de plan y fin, sólo podía ser vista como una ridícula aberración. Sería más bien un «automatón»** por su acción azarosa, ciega, espontánea y sin finalidad, que necesitaría en todo caso

$\left({ }^{* *}\right)$ Para Aristóteles, tò automatón es eso, un acontecimiento sin finalidad, al azar. Es diferente a Tyché, que se refiere a lo que ocurre, no por mera casualidad, ni por necesidad, sino por la inefable acción de la fortuna, (Aristóteles 1995: La física, Libro II, cap. 4, pág. 59). 
de la intervención inteligente del hombre para dirigir su movimiento conforme a un plan y un objetivo. De hecho, una máquina debe ser programada con arreglo a fines para garantizar una acción regular y, por tanto, «manejable», en otras palabras, «controlable»; de lo contrario, sería inútil. Lúcido y analítico, el estagirita observaba también que la fuente de poder de lo técnico está determinada por su posesión, por su carácter de lo «a la mano», escribiría Heidegger siglos después. Una máquina siempre requiere, decía Aristóteles, la intervención de un esclavo, precisamente porque el artefacto no se mueve por sí mismo. Ciertamente, escribe en la Política que «si las lanzaderas tejieran así y las púas tocaran el arpa por sí mismas, los maestros artesanos no necesitarían ayudantes ni los señores esclavos» (citado por S. Turró, 1985: 41) $)^{* * *}$.

En Aristóteles no hay miedo a las máquinas, puesto que se detecta un tono irónico al referirse a las trípodes de Hefestos y a las estatuas animadas de Dédalo; pero sí una distinción entre lo natural y lo artificial, esquema en que lo primero es superior a lo segundo por derecho propio e intrínseco. La garantía de la superioridad de la naturaleza sobre la artificialia es, desde luego, ontoteológica, puesto que se supone que ha sido creación divina, que es decir poco dentro de las exigencias actuales de fundamentación.

Aunque puede resultar risible la ingenuidad del filósofo a un lector de hoy, cuya experiencia lo persuade de los alcances de la computación y la tecnología digitalizada, es significativo que imagine un mundo sin esclavos, en caso de que él estuviera equivocado respecto a su idea de la tecnología (y se lograra un perfecto automatismo y funcionalidad operativa de los artefactos inventados por el ser humano). En efecto, si los procesos de producción y de organización de la vida social alcanzasen un control automático y computarizado absoluto, ¿qué sentido tendría la existencia de esclavos, obreros y burócratas? Este razonamiento de origen aristotélico es revelador. El razonamiento hipotético de Aristóteles apunta, sencillamente, a la sociedad sin clases presentes en las aspiraciones utópicas de la temprana modernidad. De llevarse hasta las últimas consecuencias, puede resultar más potente que cualquier propuesta de emancipación de la sociedad; es decir, haría posible la transformación de la vida moderna, ya no por la acción revolucionaria violenta de una clase social especial (la obrera), como proponía Marx; ni del uso exclusivo de la acción comunicativa (Habermas), ni de la garantía del simple ejercicio de la razón subjetiva, sino dando las condiciones para que el plusvalor sea producido por las máquinas robots y los sistemas automatizados. Si se cumplieran las condiciones de la conjetura

$\left({ }^{* * *}\right)$ La traducción de Manuela García Valdés (Editorial Gredos, España) es la siguiente: «Pues si cada uno de los instrumentos pudiera cumplir por sí mismo su cometido obedeciendo órdenes o anticipándose a ellas, si, como cuentan de las estatuas de Dédalo o de los trípodes de Hefestos, de los que dice el poeta que entraban por sí solos en la asamblea de los dioses, las lanzaderas tejieran solas y los plectros tocaran la cítara, los constructores no necesitarían ayudantes ni los amos esclavos, (Aristóteles 1988: Política, Libro I, pág. 55). 
aristotélica, es decir, la automatización absoluta, la riqueza no dependería del desgaste humano y sensible de los operadores.

\section{LA SUSTANCIA INSTRUMENTAL DEL CEREBRO HUMANO}

La tecnología y la producción de artefactos auxiliares o fundamentales en las tareas de la vida social y económica, no constituye una especie de superestructura artificiosa sobrepuesta a la capa genuina de lo "natural", —cuya solidez inamovible sería el fundamento de todo lo creado por encima de ella. ¿Por qué la burbuja generada por el jabón sería menos real que el jabón mismo? ¿No se trata sólo de un proceso de transformación? ¿La naturaleza no está hecha, acaso, de sustancias dinámicas y productoras de variedad animal y vegetal, orgánica e inorgánica?

Los procesos naturales no carecen de aspectos funcionales con los que se consigue regular y controlar las tareas específicas y necesarias a desarrollar. En la naturaleza, la fabricación de herramientas y otros recursos inventivos son tan «normales», como en la sociedad lo es la capacidad operativa de los niños para manipular sus juguetes $\mathrm{y}$, ahora, desde hace unas cuantas décadas, los celulares, tabletas y computadoras. Es suficiente una consulta rápida al texto «Animales inteligentes» de la doctora Sally Boysen (2009: pág. 20, 46) para percatarnos de los ejemplos extraordinarios de cuervos y pinzones que utilizan ramas y otros objetos como herramientas para obtener alimento. El cuervo recorta pedazos de tallos para crear sondas y pinchos que le sirven para detectar y atrapar a las presas escondidas en los recovecos y oquedades donde se ocultan; algunas nutrias utilizan piedras para romper ostiones y ciertas especies de chimpancés organizan su trabajo apoyados por cajas de herramientas, que utilizan de manera pertinente para coordinar diferentes funciones al mismo tiempo, - como asegurar el equilibrio en el agua auxiliados por un tronco a manera de bastón, mientras con una lanza sacan a la superficie hierbas húmedas para alimentarse.

El mundo microscópico parece funcionar como una fábrica productora de proteínas y otras sustancias, como moléculas partidas en trozos que se ensamblan con una precisión asombrosa, apoyados en un "plan" inscrito en los genes. El premio nobel Christian Duve, en su conocido texto La vida en evolución (2004), echa mano de una fantástica metáfora para entender cómo es que las "fábricas de la naturaleza" nunca se detienen. Nuestro cuerpo es análogo a una casa antigua; parece que no cambia, pero lo cierto es que el mantenimiento de su forma aparentemente intacta, depende de procesos constantes y silenciosos de destrucción y construcción. Es como si la casa eliminara, por sí misma, los ladrillos, tejas, cimientos y piezas viejas, para sustituirlos por elementos nuevos, elaborados a partir de fragmentos moleculares de diferentes sustancias, en especial proteínas. Es una tarea compleja, que el autor insiste en describir de acuerdo a otra de sus metáforas preferidas: la vida es, en efecto, una fábrica química donde 
se cumplen tres condiciones básicas: materias primas, energía y, «casi en todos los casos, catálisis». Algunas moléculas parecen montacargas que transportan, mueven, colocan y ensamblan como máquinas robotizadas los eslabones de otras moléculas, aminoácidos o piezas de carbono, dispuestas como partes «de un juego Lego».

«Montajes biosintéticos, transformaciones metabólicas y acoplamientos bioenergéticos implican un número muy grande de reacciones químicas, de las que prácticamente ninguna tendría lugar si las sustancias participantes simplemente se mezclaran» (De Duve C. 2004: 40). Lo nuevo no es "artificial”. Es la producción de algo que es resultado de combinaciones de elementos en una "lógica" de ensamble diferente a las ya existentes, a la manera de un rompecabezas que al estructurarse es capaz de crear nuevos paisajes, nuevas utilidades y funciones. De forma análoga, las herramientas y la tecnología en general no pueden concebirse como una simple extensión del cuerpo, como una prótesis artificialmente agregada a un ser vivo, puesto que responden a un modo de ser propio del ser humano, que es un animal naturalmente operador y coordinador de funciones $\multimap$ tanto individuales, como cooperativas o sociales.

El organismo humano se comporta él mismo como una máquina inteligente que coordina funciones, ensambla, construye y articula de manera análoga a las moléculas que «reconocen»a otras como piezas de una misma construcción.

Así como las habilidades corporales inteligentes —danzar, un acto de atletismo, la habilidad de un guitarrista - asombran, enseñan y revelan aspectos nunca antes vistos o imaginados del mundo sensible, así la tecnología expresa con sus funciones maquinales aspectos antes no conocidos de la naturaleza. El avión supersónico nos da idea de las relaciones físicas de la velocidad y de las condiciones necesarias para mantener un objeto pesado suspendido en el aire; nos permite entender a las águilas, a los halcones y a las aves que parecen solazarse en su capacidad de planear y mantenerse por tiempo indefinido entre las nubes. Se trata de relaciones que los seres humanos podemos codificar en lenguaje científico para comunicarlo. Las abstracciones encriptadas en ese lenguaje nos facilitan entender lo que sensiblemente nos asombra al ver o descubrir los fenómenos de la naturaleza. Este asombro ante los fenómenos naturales es primigenio y "anterior", por supuesto, a nuestra capacidad de codificar las relaciones de la naturaleza en un código científico; pero sin esta tarea ardua, paciente y difícil que exige habilidades nuevas derivadas de la capacidad de abstracción, no seríamos capaces de ampliar nuestra comprensión de la naturaleza y su aprovechamiento; como tampoco seríamos capaces de entendernos un poco más a nosotros mismos.

¿Pero por qué nos despierta temor y desasosiego algo, en última instancia, "natural”? Desde nuestro punto de vista, las fuentes del temor a la razón instrumental derivan de la propiedad de desanclaje de los artefactos y procesos producidos tecnológica y científicamente por ella. Ya se ha podido entrever 
que la naturaleza de esta propiedad propicia la despersonalización de los procesos y la rigidez de sus reglas, tan extrañas a la espontaneidad y libre naturalidad de la conducta humana.

El desanclaje nos presenta los artefactos y medios como externos y autónomos. Una herramienta está construida para cumplir funciones donde se necesiten, en cualquier tiempo y lugar, sin que le afecte que Pedro, Juan o Sofía sean sus operadores, siempre y cuando tengan el conocimiento procedimental suficiente para utilizarla. Tanto el conocimiento funcional como su realidad material mecanizada tienden a independizarse de la individualidad de las personas: forman parte constituyente del mundo instrumental, que posee cierta autonomía respecto de nosotros, los seres vivos. Nosotros, operadores transitorios, dejaremos de existir cuando termine nuestra vida; pero ese mundo instrumental-funcional seguirá su curso y seguirá demandando operarios de carne y hueso a medida que lo necesite.

Esa autonomía funcional, desde nuestro punto de vista, es de dos tipos. La autonomía funcional simple se refiere al hecho de que un objeto-máquina (u objeto-herramienta), en cuanto es materialmente independiente de nuestra corporeidad, puede ser usado —según se aludió arriba— por cualquier individuo, una vez entendida o descubierta su función en un entramado de relaciones operativas (RO) semiotizadas. Una piedra usada como martillo, cumple esta función, independientemente de que la mano que la emplea sea de Juan o de la nutria de Sally Boysen.

Una piedra usada como herramienta no pierde su "naturaleza" de piedra; pero en cuanto se inserta en un marco distinto de relaciones operativas, entonces diversifica su función. En este sentido, las RO son semióticas: al funcionalizar los objetos, cambian los significados en un nivel de abstracción y generalización distinto, que se puede representar según el esquema de Umberto Eco. Semiotización quiere decir que una función descubierta se codifica en un significado socialmente generalizable y transmisible, que remite un caso (la piedra particular o token, que acaba de ser descubierta para ser usada como martillo) a un conjunto de casos o type en el que muchas piedras pueden realizar la misma función independientemente de sus características concretas (Eco U. 1980: 59).

La semiotización de las relaciones operativas es lo que da la impresión de "artificio"; pero la piedra sigue siendo piedra, aunque ya deje de estar ahí como parte del paisaje y se use para golpear, descalabrar al prójimo o abrir el duro caparazón de un ostión. El hecho es que la nutria, el chimpancé o el ser humano han captado un desconocido haz de relaciones en la naturaleza, donde el objeto en cuestión muestra utilidades no descubiertas antes, partiendo de las mismas e inalterables relaciones físicas. Es decir, las condiciones básicas del mundo físico, en cuanto tales no cambian por el hecho de construir un avión supersónico; pero sí trae consecuencias, cuando, por ejemplo, el combustible utilizado resulta contaminante. 
Ahora se ve claro como este fenómeno de desanclaje semiótico se convierte en motivo de mitos en el imaginario humano: creer que la piedra cobra vida propia o es movida por una mano invisible (como la de Adam Smith), puede asustar a unos, pero también maravillar a otros, dependiendo de la intención dramática del relato.

La autonomía funcional compleja, que es el segundo tipo de desanclaje que proponemos, hace realidad el mito de Efesto —citado por Aristóteles—, en el que los artefactos actúan por sí mismos de manera automatizada o robotizada, como si poseyeran un alma etérea que las dirige para "dominar" y "esclavizar" a los seres humanos. Pero la funcionalidad automática depende del conocimiento del sistema de relaciones operativas correspondientes, que es posible codificar y expresar mediante algoritmos, a fin de instrumentar los patrones de programación de un robot o artefacto. En una máquina robotizada, no es necesario que el ser humano se adhiera como apéndice, como Charlot al engranaje.

Los seres humanos somos «portadores» de la «sustancia instrumental»y productora -ya supuesta en la espontaneidad del mundo natural. Siguiendo a Habermas, además de razón subjetiva, poseemos razón instrumental y no podemos despojarnos de ninguna de ellas. Nuestro cerebro, según los neurólogos, posee estructuras con funciones ejecutivas que hacen posible las tareas operativas individuales; pero también posee estructuras «neurosociales» que admiten el ensamble de otros seres humanos en tareas coordinadas, como lo hacen otros animales con diferente estructura morfológica, como los lobos, que cazan en grupo y en una lógica de "alta dirección" asombrosa, pero también con un sentido de justicia distributiva a la hora de repartir el botín. Sin embargo, en una actividad como la caza de grupo, el cuerpo es el eje instrumental de las ejecuciones coordinadas: los delfines se sirven de sus cualidades hidrodinámicas para alterar las condiciones acuáticas, con la finalidad de impedir el nado rápido de sus presas; los lobos utilizan la flexibilidad y la velocidad de su cuerpo para acorralar al "objetivo", dejándolo sin posibilidad de escape. Sin embargo, las capacidades corporales por sí solas, en humanos y animales, no garantizan altas probabilidades de éxito. Es necesaria una estrategia, que es en parte producto del instinto y en parte del aprendizaje.

No obstante, sólo el ser humano puede realizar «jugadas de pizarrón» y utilizar herramientas sofisticadas para ejecutar sus acciones productivas. Su capacidad de abstracción le permite aislar en una simbología apropiada las relaciones operativas para la realización rápida y eficiente de las ejecuciones. Es decir, puede separar las tareas de dirección de las ejecutoras; aislar las relaciones abstractas, respecto del ámbito de operaciones concretos. Así, los símbolos se adaptan a la manipulación y viceversa: una simple palanca representa relaciones operativas (cambios de velocidad), y al mismo tiempo los activa en un proceso mecánico complejo; las teclas del ordenador están articuladas de acuerdo a un lenguaje operativo y por eso mismo es posible dirigir tareas informáticas previamente programadas. 
La modelización (las jugadas de pizarrón) es expresión de la capacidad de desanclaje de las competencias humanas, las cuales se vuelven transferibles a otros individuos, -independientemente del tiempo y del espacio— sólo si estos se entrenan en los dominios simbólicos que prescriben sus operaciones. Dan la impresión de constituir esferas independientes, "flotantes" y "espirituales", como en otro tiempo la mitología imaginó el alma humana, lo cual no es casual: nuestro cerebro opera a partir de modelizaciones para cotejar la información pasada con la actual. Y esas modelizaciones tienen la posibilidad de comunicarse. Entender que este libro que veo en el escritorio, es un libro y no una cosa diferente, está determinado por información incesantemente cotejada entre los sistemas de percepción central (memoria visual exitosa o auto-comprobada) y las sensaciones efectivas de entrada. Si un niño coge este mismo libro y lo considera un coche para jugar, está también modelizando, pero en unas relaciones operativas distintas, aunque en un mismo plano físico: los actos operativo-intelectuales del libro ya no son abrir el texto-hojearlo-leerlo; para el niño son deslizarlo por el escritorio-carretera y atribuirle sonidos de motor.

Las figuras de la imaginación, tanto como las ideas y las imágenes del sueño, son modelos de la realidad procesados por el cerebro para orientar la acción y el pensamiento. Dan la impresión de ser contrapuestos a la realidad (a pesar de representarla, imperfectamente si se quiere) y de poseer vida independiente, como los seres divinos y mitológicos, a los que se teme o se les rinde culto. Ello explica que el trabajo intelectual, que empezó a volverse más complejo a medida que la división del trabajo discriminó las tareas manuales, adquiriera un carácter sacro y se reputara como más importante y digno que cualquier otra actividad. Esto comenzó a cambiar con el surgimiento de la idea de "profesión" en el marco de la reforma de Martín Lutero en el siglo dieciséis, sobre lo que reflexionaremos en el siguiente apartado.

\section{LA FIABILIDAD DE LOS SISTEMAS EXPERTOS Y SIMBÓLICOS}

El cerebro humano está dotado, pues, de la capacidad de simbolizar. Se trata de una de las destrezas más extraordinarias porque, con ella, puede encriptar una gran cantidad de significado en unos cuantos caracteres manipulables. La figura de una flecha puede representar a la guerra en general (inclusive todas las guerras posibles); o bien, puede significar el carácter de aquellos que han mostrado arrojo en el combate (valentía); o bien, como en el mundo moderno, puede significar sencillamente el sentido de una calle. Un punto puede significar el átomo, como entre los griegos; un elemento irreductible, o bien el objeto geométrico más simple, del que parten todas las demás figuras. La polisemia no es un defecto: es la propiedad de signo que autoriza varios significados, según el sistema semiótico en que se inserte. Facilita la manipulación mental de una cantidad inimaginable de información del mundo externo o interno. 
Por ejemplo, ¿qué tanto nos hace pensar la palabra "Dios" —cuatro letras sintácticamente articuladas— sobre la subjetividad humana? Un mundo inagotable de reflexiones de carácter metafísico.

La acción operativa del ser humano se ha pensado, en todas las culturas, como trabajo, producción y, en general, en término de modalidades del obrar. Se ha distinguido siempre entre trabajo puramente material que cualquiera puede realizar con un poco de entrenamiento, y trabajo con un grado de destreza más elevado, dependiendo del oficio. Las culturas antiguas garantizaban la destreza operativa con una división del trabajo avalada por los dioses tutelares. Con ello se aseguraba que las familias se dedicaran, de generación en generación, a un mismo oficio (herrero, zapatero, esclavo incluso). En cuanto al trabajo intelectual, existían las castas de sacerdotes, escribas, administradores y consejeros de la corte, que debían asegurar la confianza en las decisiones concernientes a cada una de ellas, para mantener la estabilidad del reino.

En la edad media, sea dicho irónicamente, no se hablaba en términos de «calidad» de los procesos de producción de "cosas útiles" como en la actualidad; se reflexionaba sobre el valor del obrar mismo. Es decir, se ponía el acento en el sujeto, no en el objeto. Los términos se invirtieron con el desarrollo del capitalismo, a causa de la despersonalización de las acciones y las habilidades, inherente a los procesos de desanclaje: Marx habla de cosificación, Weber y Parsons de desanclaje y la escuela de Frankfurt de razón instrumental.

El trabajo simple —concepto de Carlos Marx—; es decir, aquel puramente manual, tosco y grosero por apenas demandar algo de actividad intelectual, era por supuesto el más despreciado. Basta recordar un pasaje del genial Max Weber, del texto antes citado, para darse una idea de esta escala de preferencias sociales, basada en el criterio altamente abstracto (altamente simbólico) de la glorificación de Dios.

Además de la fe, es necesario establecer con certeza qué es lo más digno de hacer en el mundo para no traicionar esa fe y a la divinidad, máxime que los protestantes rechazaban por "inauténtica" la vida monacal católica. Habría que buscar la ascesis, la glorificación de Dios, en el exterior, en el mundo, no en el encierro en el monasterio; de ahí la importancia dada a la idea de "profesión". Para el caso de los obreros y trabajadores manuales, no había tanto problema, pues el hecho de permanecer obedientes y pobres ya era suficiente para ser amados por el Señor (declaración de Lutero, según Weber 2004: 230). A partir de esta aseveración luterana, «toda la literatura ascética de todas las confesiones se empapó de esta idea de que también el trabajo fiel con salarios bajos para aquellos a quienes la vida no les ha concedido otras oportunidades es algo muy grato a Dios» (Weber 2004: 231). En cuanto a la profesión, debía ser considerada el único medio para estar seguro del estado de gracia, como subraya ahí mismo Weber.

La profesión exige disciplina y entrega para repetir abnegadamente procesos productivos de forma sistemática, de preferencia aquellos que den garantían del acrecentamiento de la riqueza, que 
originalmente se persigue, no por vulgar apetito, sino porque la riqueza es fuente de servicio y mantenimiento de una dimensión cada vez mayor de seres humanos, considerados criaturas de Dios. Es decir, la obtención de riqueza es una forma de glorificación divina. Pensar en la manutención individual es vulgar y egoísta, del mismo modo que resulta deplorable la actividad del obrero que sólo trabaja para sobrevivir o por "necesidad externa". El obrar productivo debe estar conectado a una idea elevada, espiritual, no a una exigencia sensible y contingente. El amor al prójimo sólo puede ser un servicio a la gloria de Dios, no de la criatura (Weber 2004: 125). En general, el obrar productivo posee más valor en cuanto se conecta a una necesidad interior.

La religión luterano-calvinista, en ese sentido, promueve el desanclaje de relaciones operativas cada vez más complejas e independizadas de las labores arraigadas en el mundo terrenal. La productividad se sujeta indefectiblemente a reglas abstractas, $\multimap$ desconocidas entonces, pero operantes - , que por lo mismo entrañan incertidumbre, despiertan ideas místicas y terrores nuevos. Una actividad de gran complejidad técnica como la minería, por ejemplo, depende de transacciones cada vez más complejas, de transferencias monetarias que van de mano en mano, para mover toda la maquinaria social necesaria para producir oro, plata y cobre. En la época de Lutero, cuyo padre era minero, se habían realizado innovaciones tecnológicas que supuso manejos instrumentales cada vez más complejos de parte de operarios, pero también grandes inversiones para la adquisición y compra de las mismas. Aunado a ello, se exigían nuevas leyes del derecho para asegurar una justicia distributiva y, por tanto, la certidumbre de las transacciones económicas, para no correr el riesgo de matar la gallina de los huevos de oro (las minas) con el empobrecimiento de los obreros calificados y de los intermediarios encargados de proveer innovaciones tecnológicas.

Hay un pasaje en el espléndido libro de Lyndal Roper Martín Lutero, renegado y profeta (2017) que retrata con precisión tales condiciones. «No había ninguna teoría económica y no acababan de entender cómo se generaba la riqueza: nadie sabía por qué los inversores de Nüremberg y Leipzig obtenían beneficios, mientras los propietarios se empobrecían de repente. La economía se basaba en la idea de que la riqueza era limitada. Si una persona poseía muchas riquezas, otra no podía obtenerlas. Se creía que los metales procedían de la aleación de mercurio y azufre y que estaban bajo la influencia de los planetas, de manera que la minería también era una cuestión de buena fortuna. Había adivinos y se publicaban libros de consejos, pero nadie sabía dónde se ocultaban las mejores vetas», (Roper L. 2017: 31). La acción humana tenía, como siempre consecuencias imprevistas y retos inconmensurables, puesto que cualquier sistema posee algún coeficiente de incertidumbre, dependiendo de la cantidad de información y de energía necesaria, que tal sistema exige para funcionar. En la minería de los tiempos de Lutero, sólo Dios podía ser el árbitro de unas relaciones productivas tan complejas creadas por los seres humanos y con funciones 
tan nuevas: obreros tecnificados para quienes la improvisación representaba un riesgo, e inclusive su propia existencia exponía la productividad, porque difícilmente podía ser sustituida por alguien igualmente calificado, en caso de accidente o muerte. Era necesario crear «profesionales» de una forma sistemática. También se necesitaban administradores capaces de garantizar la autoprotección de la actividad productiva, cosa que no había: los condes controladores de las minas debían fiarse de la intuición para acaparar dividendos, sin merma de la productividad. Es decir, ni siquiera había "empresarios" en el sentido actual del término. Quienes cumplían funciones de ese tipo eran gente de la nobleza, autorizada por los príncipes.

Lyndal Roper escribe sobre las esperanzas del padre de Lutero de que su hijo estudiase derecho, porque esta disciplina abstracta era la única que, a su juicio, podía garantizar la protección del negocio familiar. Las relaciones operativas creadas a partir de la creciente complejidad tecnológica, plantean la necesidad de crear sistemas expertos y de sistemas de códigos, reductores de incertidumbre, cuya función es otorgar fiabilidad o confianza social de término medio. No es nada casual que el surgimiento de las universidades en Europa en el siglo XIII esté vinculado a dos fuentes de incertidumbre: la salud y la justicia, es decir, a la necesidad de conocimientos en derecho y en medicina. Una vez constituidos los sistemas expertos, estos se independizan de la localidad y tienden a despersonalizar las relaciones, como ocurre, por ejemplo, con el dinero, escribe Anthony Giddens en Consecuencias de la modernidad (1994). «Todos los mecanismos de desanclaje, así sean señales simbólicas o sistemas expertos, descansan sobre la noción de fiabilidad», indica; «pero esa fiabilidad no se confiere a individuos sino a capacidades abstractas. Cualquiera que utilice los símbolos monetarios, lo hace asumiendo que los otros, a los que nunca ve, respetarán su valor» (Giddens A. 94: 36). El análisis del concepto de fiabilidad que realiza Giddens es demasiado exhaustivo; pero llama la atención sobre una arista importante: la fiabilidad de los sistemas expertos y simbólicos descansa en la correlación de unos principios que el usuario ignora. Puede que nosotros no sepamos cómo funciona un ordenador, pero nos otorga tantas certezas de funcionalidad que nos fiamos de los expertos programadores cuando algún fallo interrumpe mis actividades de oficina; algo parecido ocurre con mi salud, cuando se la confío a la medicina como sistema experto, que autoriza su ejercicio a unos individuos «profesionales» y no a cualquiera.

En el caso de los mineros de los tiempos de Lutero, no contaban con sistemas de fiabilidad para reducir la incertidumbre y los riesgos de las decisiones operativas importantes. Los sistemas expertos y simbólicos (financieros) se desarrollaron en una marcha de siglos, no siempre de manera complementaria con la creación de las innovaciones tecnológicas. Esa disparidad entre los diferentes sistemas, la oposición y el conflicto entre ellos, fue en realidad la tónica en el desarrollo del capitalismo, lo que habla de una modernidad todavía inacabada, a pesar de los avances y la complejidad cultural de la sociedad actual. 
¿Cuándo podremos hablar de modernidad plena o inclusive de posmodernidad? Cuando logremos la automatización y robotización absoluta de los procesos burocráticos, como visualizaba Aristóteles, no sin cierta ironía.

La racionalidad instrumental no constituye una «perversión» de la razón natural, ni siquiera por sus consecuencias nefastas: cualquier sistema complejo posee márgenes de inconmensurabilidad, esto es, a consecuencias incontrolables y ruidosas. Desde que nos manteníamos como cazadores y recolectores organizábamos el trabajo como una «máquina social», ciertamente imperfecta, pero sí coordinada. La diferencia es que también funcionaba una justicia distributiva. En el mundo prehistórico, el cuerpo entero debía mantenerse como una máquina eficiente, lo suficientemente ágil como para garantizar una función exitosa. De hecho, ningún animal más o menos desarrollado se lanza de forma arbitraria a la búsqueda de un suculento cuerpo vivo, al que debe atrapar si se quiere sobrevivir. Los documentales sobre el mundo animal dan cuenta del despliegue cuidadoso de acciones coordinadas, así como de formas de acecho y estudio de la eventual presa, antes de decidir una acción final con garantía de éxito.

El éxito no es un concepto puramente subjetivo; es una noción importante porque el sistema de la vida comporta precisamente riesgos; en todo caso nos persuade de que la naturaleza emocional juega un papel tan importante como el carácter instrumental de nuestra corporalidad: necesitamos confianza en nosotros mismos (y en nuestros semejantes cooperativos), o apoyarnos en un poder trascendente - un dios - que nos otorgue la impasibilidad de un robot perfecto, vivo y preciso para no fallar en la acción, sobre todo cuando se da en un contexto peligroso. En ese marco, el éxito se convierte en un elemento catártico: se conjura el riesgo cuando ganamos algo, por lo menos la esperanza.

Por tanto, las fuentes del temor a la racionalidad, las fantasías terroríficas en contra del progreso, tan adheridas a la vida moderna, se deben encontrar no en las máquinas, sino en otro lado más oculto o menos evidente: en la incertidumbre de los sistemas tecnológicos, pues $\bullet$ en lo que va de historia de la tecnología- las innovaciones tecnológicas solucionan unos problemas, pero dejan abiertos otros, como es el caso de los ecológicos, que después de siglos de capitalismo apenas empezamos a reconocer.

Cuando nos preguntamos, como los animales inquietos que somos, sobre la probabilidad de que los robots lleguen a ser tan poderosos e inteligentes como para someternos a una esclavitud, es porque nuestras tecnologías siguen siendo imperfectas y tememos, por ello, que se salgan de nuestro control. ¿Pero qué interés tendrá un robot en «explotarnos», si existirá la capacidad de crear máquinas y sistemas más eficientes que nosotros? El robot puede trabajar sin merma alguna: sus piezas pueden ser sustituidas o incluso mejoradas, e incluso puede ser sustituido por un robot más capaz, sin provocarle celos profesionales (al menos que un hombre lo programe emocionalmente). Quizá no seremos operativamente superiores a ellos, pero existirá la probabilidad de que nuestro organismo pueda repararse con tecnología 
biomédica o biónica, como lo prefiguran los cómics que relatan fantasías de héroes creados por la tecnología.

Por otra parte, al robot no es necesario pagarle por crear plusvalor, concepto tan caro al marxismo, por atribuirle al obrero una propiedad «histórica» especial, como clase, para realizar la revolución que habría de abolir, de manera violenta y definitiva, el sistema capitalista explotador. La revolución vendrá, en realidad, de la automatización tecnológica de la sociedad; del carácter liberador de las máquinas que anticipó, en un acto de razonamiento hipotético genial, el venerado Aristóteles: al ser sustituido por un robot, el obrero queda liberado de ser un deplorable apéndice, que tantos sentimientos de indignación y mitos ha despertado en políticos e intelectuales.

Si ya no es el obrero el creador directo de plusvalor - que genera, a su vez, las ganancias privadas del capitalista-, ya no es necesaria una revolución sangrienta para cambiar esa condición. Tampoco es necesario el capitalista, puesto que el cálculo de mercadeo y finanzas puede realizarlo un ordenador autónomo con poder cuántico. Los verdaderos retos humanos dependerán, entonces, de la complejidad generada por la automatización absoluta; esto es, de las nuevas fuentes de incertidumbre ecológicas, cósmicas y naturales, capaces de plantear retos cognoscitivos de envergadura, que podremos realizar en coordinación con las máquinas.

Estamos de acuerdo con Horkheimer y en la escuela de Frankfurt, en perseguir un fin emancipatorio, a condición de articular un programa de aceleración paulatina de la automatización de los procesos productivos y burocráticos de la sociedad. Hará falta un programa político-económico que se apoye en lo que el citado filósofo denomina racionalidad subjetiva, esto es, el ámbito de experiencia del individuo vivo que confiere ventajas a sus potencias intelectuales. El programa implicaría socializar el plusvalor generado por las máquinas automáticas: la instauración de un salario básico universal, la reconducción de inversiones hacia la creación de procesos robotizados, el cuidado de la ecología y el cuidado de los otros (educación, medicina, geriatría, demografía, etc.). El plusvalor dejaría de poseer un carácter privado, para convertirse en plusvalor social administrado por un sistema de justicia distributiva. 


\section{BIBLIOGRAFÍA}

Adorno, T. (1962). Prismas, la crítica de la cultura y la sociedad, traducción de Manuel Sacristán. Barcelona: Ariel

Aldoux, H. (2020). Un mundo feliz. México: Editorial Edisur

Aristóteles (1988). Política, Introducción, traducción y notas de Manuela García Valdés. Madrid: Editorial Gredos, Madrid

-- (1995) Física, Traducción y notas: Guillermo R. de Echandía. Madrid: Planeta de Agostini. Eco, U. (1980). Tratado de semiótica general. Barcelona y México: Nueva imagen + Lumen

Duve, C. (2004). La vida en evolución, moléculas, mente, significado, traducción de Joandomènec Ros. Madrid: Crítica Dakontos

Weber, M. (2004). La ética protestante y el espíritu del capitalismo, traducción de Joaquín Abellán. Madrid: Alianza Editorial.

Horkheimer, M. (1973), Crítica de la razón instrumental, versión castellana de H. A. Murena y D. J. Vogelmann. Buenos Aires: Ed. Sur

Orwell, G. (2020). 1984 traducción Maritza Izquierdo. Madrid: Editorial Verbum

--La rebelión en la granja. (2014). Chile: Zigzag Ediciones

Roper, L. (2017). Martín Lutero, renegado y profeta. Barcelona: Penguin Random House, Grupo Editorial.

Turró, S. (1985). Descartes, del hermetismo a la nueva ciencia. Barcelona: Anthropos ARTÍCULOS

Carvajal Ahumada, G. (2010) Todo sujeto es sujeto de la técnica. Tecnología y subjetividad en la filosofía griega clásica Análisis. Revista Colombiana de Humanidades, núm. 76, pp. 173-192 Universidad Santo Tomás Bogotá, Colombia.

Hernández Reynés, J. (2009). Lo natural y lo artificial en Aristóteles y Francis Bacon. Bases para la tecnología moderna, www.ontología.net Barcelona, Ontology Studies 9, 289-308. 